\title{
Diethylstilbestrol as a Temporary Chemos- terilant to Control Black-tailed Prairie Dog Populations
}

\author{
MONTE G. GARRETT AND WILLIAM L. FRANKLIN
}

\section{Abstract}

Controlling reproduction in pest rodent populations may be preferable to using lethal rodenticides. The effectivenss of diethylstilbestrol (DES), a synthetic estrogen, as a reproductive inhibitor in female black-tailed prairie dogs (Cynomys ludovicianus) was examined in a 4-year study at Wind Cave National Park, South Dakota. In 1979 and 1980, a study colony was monitored to determine age structure, reproductive success of individual animals, and rate of colony expansion. In 1981, the colony was divided into control and experimental areas. Application of DEStreated oats (.11\% active ingredient) during the breeding season resulted in complete curtailment of reproduction in the experimental group while reproduction in the control group was normal. Results were identical in 1982 when treatment was reversed. There were no obvious effects of DES treatment on subsequent reproductive capability of study animals. In 1981, surface expansion of the study colony was $4 X$ less on the DES-treated side compared with control.

In recent years, research in the use of chemosterilants to control pest rodent populations has been increasing (Howard 1967, Knipling and McGuire 1972, Marsh 1973, Marsh and Howard 1970, 1973,1976 ). Chemosterilants reduce the need for lethal rodenticides by concentrating management efforts on reducing natality rather than on increasing mortality. It is more practical to prevent the birth of animals rather than to reduce their numbers after they are fully grown and established in a secure environment (Basler 1964a). Further, chemosterilants are less toxic in baits than rodenticides and pose less hazard of killing humans, pets, or domestic animals (Brooks 1973).

Bennetts et al. (1946) first reported that plant estrogens in subterranean clover (Trifolium subterranean) reduced reproductive success in sheep (Ovis aries), and Davis (1961) conducted one of the first experiments in the use of estrogens to control rats (Rattus norvegicus). Howard and Marsh (1969) and Marsh and Howard (1969) reported mestranol (a synthetic estrogen) to be an effective reproductive inhibitor for several rodent species $(R$. norvegicus and Microtus spp.). Because such nonsteroidal compounds are inexpensive, highly potent, and effective when taken orally, they

\footnotetext{
Authors are graduate research assistant and associate professor, respectively, Authors are graduate research assistant and associate professor,
Department of Animal Ecology, lowa State University, Ames, 50011 .

this publication reports research and recommendations for the use of a chemosterilant to control prairie dogs. It does not imply that uses discussed here have been registered. Chemosterilants must be registered by appropriate state and/or federal agencies before incorporation into a management plan.

This study was funded by the National Park Service (CX-1200-0-B020) and Iowa State University. Journal Paper No. J-10800 of the lowa Agriculture and Home Economics Experiment Station, Ames. Project No. 2348.
}

The authors thank Lester McClanahan, Richard Klukas and the entire staff of Wind Cave National Park for their cooperation and assistance throughout the study period. Roger Pearson, South Dakota Department of Agriculture, supplied oats and the facility for mixing DES. The assistance of Bill Bunger, Joan Graden, Susie Garrett, and Ahmad Abdunabi in data collection is greatly appreciated.

IDES was obtained from the Sigma Chemical Company, Box 14508, St. Louis, Mo. Diethylstilbestrol as a Temporary Chemo-sterilant to Control Black-tailed Prairie Dog Populations are good candidates for chemosterilants.

Although extensively used to increase growth rates in domestic livestock (Trenkle and Burroughs 1978), the antifertility effects of the synthetic estrogen diethylstilbestrol (DES) have been tested with few species. Travis and Schaible (1962) noted reduced embryo counts in mink (Mustela vison) treated with DES. Linhart and Enders (1964) reported good bait acceptance and termination of pregnancy in Des-treated captive red foxes (Vulpes vulpes), but field tests indicated insignificant reproductive effects in wild foxes (Allen 1982). The number of female coyotes (Canis latrans) successful in breeding was significantly reduced after consuming DES-treated baits in a field trial (Balser 1964b), but no effect was reported in wild skunks (Mephitis mephitis) (Storm and Sanderson 1969). Study of antifertility effects of DES in rodents has been mostly limited to lab studies (reviewed by Saunders 1968). However, Pfeiffer (1972) conducted a preliminary study on DEStreated wild populations of black-tailed prairie dogs (Cynomys ludovicianus).

Prairie dogs have been a problem in range management since the western grasslands were first tilled or fenced for the production of crops and livestock (Koford 1958). These herbivorous rodents reduce graminoid standing crop in the vicinity of their colonies and are considered a competitive threat to domestic and other wildlife grazers (Bonham and Lerwick 1976, Hansen and Gold 1977, Klatt and Hein 1978). Although the use of rodenticides has reduced numbers of prairie dogs to a fraction of their original range, this approach has not been altogether satisfactory. In situations in which population reduction is desirable over complete eradication, a temporary chemosterilant may be an effective management tool alone or when used in conjunction with lethal control. As Howard (1967) points out, poisoning large numbers of animals is of little value without some means of preventing or slowing recovery.

Prairie dogs are large, colonial ground squirrels indigenous to the North American shortgrass prairie. Prairie dog colonies are characterized by the presence of burrow mounds and modified vegetation. Colonies are subdivided into socially cooperative family units called coteries (King 1955). Individuals of the same coterie restrict their activities within a well-defined coterie territory, which they defend against individuals of other coteries. Prairie dogs are polygynous; a coterie typically contains one adult male, 3-4 females, and several yearlings and juveniles of both sexes (Hoogland 1981).

In northern latitudes, prairie dogs breed from late February through March. Gestation is about 34 days, infants remain underground for an additional 5-6 weeks, and weaned juveniles emerge from natal burrows in May and early June (King 1955, Hoogland 1982, Garrett et al. 1982). Individuals of both sexes usually first breed as 2-year-olds, but breeding by yearlings is common in some years (Tileston and Lechleitner 1966, Hoogland 1982, Garrett et al. 1982). Females usually remain in the natal coterie for their entire lives, whereas males generally disperse during their second year (Hoogland 1982, cf. Garrett 1982). 
Several biological characteristics of prairie dogs make them particularly suited for control with chemosterilant: (1) prairie dogs are monoestrus and therefore would require only one treatment a year to curb population growth; (2) effects on nontarget species would probably be minimal because the prairie dogs' breeding season occurs during winter, when most other small herbivorous mammals are inactive and seed-eating birds are not nesting; (3) prairie dogs usually chase away other small mammals that enter their colony (King 1955), further reducing chances of chemosterilant effect on nontarget species; and (4) prairie dogs are gregarious and populations are sedentary, which makes treatment easy and efficient. In addition, it is possible that reproductive control would be more acceptable to those with strong convictions against the killing of wildlife.

Pfeiffer (1972) reported a smaller percentage of pregnant females sampled from DES-treated colonies in South Dakota. However, he did not find significantly lower juvenile:adult ratios between treated and untreated populations, making these results difficult to interpret. In any given year, reproductive performance may vary greatly among females of different colonies (Garrett et al. 1982). Yearlings produce smaller litters than do adults (Koford 1958) and exhibit estrus later than adults (Foreman 1962), reducing chances for copulating and securing an adequate nest burrow. Thus, a knowledge of female age structure and reproductive histories of colonies tested is required to accurately assess the effects of chemosterilant treatment.

Specific objectives of this study were (1) to test the use of DES as a reproductive inhibitor in prairie dogs, (2) to determine the effects or reduced reproduction on colony surface expansion (i.e., area of modified vegetation), and (3) to examine the effect of DES on the subsequent reproductive success of treated individuals. If DES is an effective temporary chemosterilant, then treated females should be able to produce normally the following year. If treatment results in lower animal density, then colony surface expansion should decrease compared with an untreated area with higher animal density.

\section{Materials and Methods}

A colony is defined as the physical area inhabited by prairie dogs. The population refers to the prairie dogs inhabiting the colony. Thus, colony expansion refers to increases in numbers of burrows and area of modified vegetation. Age classes are defined relative to the February breeding season: juveniles are individuals $\leq 7$ months postemergence, yearlings 8 to 20 months, and adults $>20$ months postemergence.

Field research was conducted in Wind Cave National Park (WCNP), South Dakota. The area is described in detail by King (1955). Prairie dogs in WCNP are protected from shooting, poisoning, and other forms of human disturbance. The study colony was located in sec. 6, T. 6 S., R. 6 E. on an ephemeral watercourse in Wind Cave Canyon. This population has been rapidly growing since its discovery in 1976, and although colony surface expansion occurred at all times of the year, expansion was most rapid during the months of peak animal density following the emergence of juveniles (Garrett 1982). The colony expanded from 0.5 ha in 1979 to 2.5 ha in 1982.

The behavior and reproduction of prairie dogs at the study colony was monitored during 4 reproductive seasons from May 1979 to June 1982 . To obtain accurate information on individual animals, all prairie dogs were periodically captured and marked with eartags and fur dye. Juveniles were captured immediately after emerging from natal burrows. Procedures used for livetrapping, handling, and marking prairie dogs are outlined by Hoogland $(1977,1979)$. Data were recorded by observing the animals from an observation blind.

The colony was mapped at regular time intervals, and a planimeter was used to measure colony expansion. Coterie compositions and territorial boundaries were determined as described by King (1955) and Hoogland (1981).
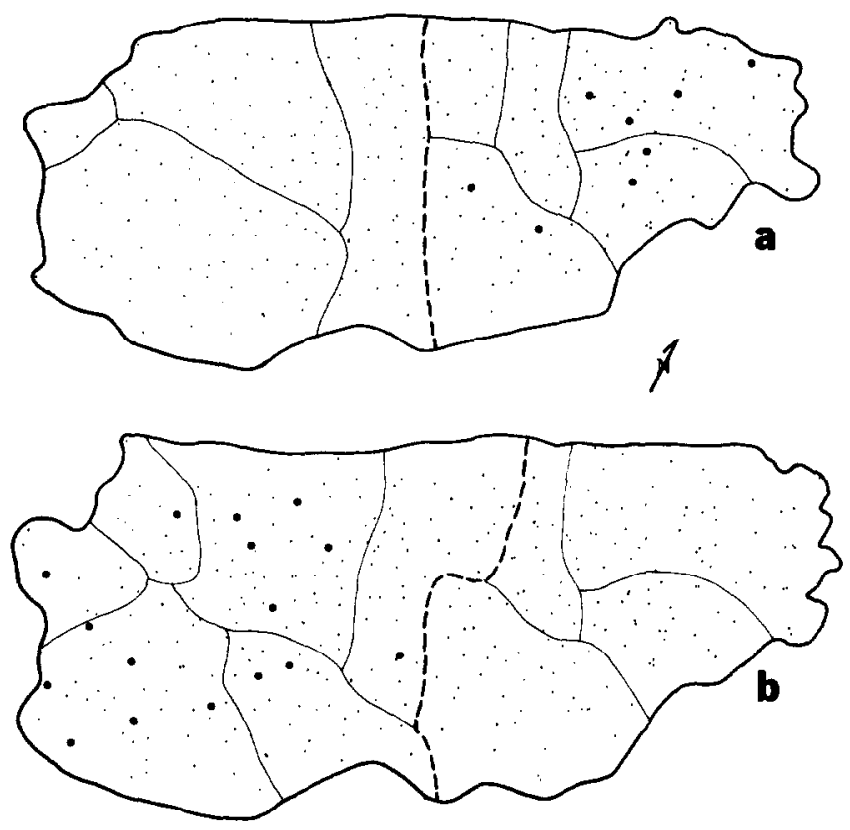

Fis. 1. Wind Cave Canyon prairie dog colony 1981 (a) and 1982 (b). Area of modified vegetation indicated by heavy solid line. The heavy broken line distinguishes the experimental and control areas. Coterie territory boundaries are delineated by thin solid lines. Burrows (dots) from which litters emerged are circled.

The study colony was divided into east and west sides, the sides serving as experimental units. In 1981 , the west side consisting of 4 coterie territories and 21 females (11 adults, 10 yearlings) was the experimental area; the control area on the east side consisted of 5 coterie territories and 13 females ( 9 adults, 4 yearlings) (Fig. 1a). Treatment was replicated in 1982: the east side was the experimental area with 20 females ( 9 adults, 11 yearlings), and the west side was the control with 18 females (all adults) (Fig. 1b). Because of changes in territorial boundaries, the 1982 delineation of experimental and control areas was determined by the residence of females (i.e., females not treated in 1981 received DES in 1982, and vice versa).

Numbers of productive and unproductive females in the pretreatment years (1979 and 1980) were compared to determine differences between east and west sides. The same analysis was used for 1981 and 1982 to determine the effect of DES treatment on control and experimental sides. To account for possible confounding effects of the DES treatment to the west side in 1981, reproductive success of females of the west (control) side in 1982 was compared with that of females in 1979 and 1980.

Twenty-five grams of DES were mixed with $22.7 \mathrm{~kg}(50 \mathrm{lb})$ hulled oats, $13 \mathrm{~g}$ yellow dye, and $156 \mathrm{~g}$ lipoidal (Pfeiffer 1972). Mixing was facilitated by the state bait-mixing station, Pierre, $\mathbf{S}$. Dak. One cup of the DES-oat mixture $(.11 \%$ active ingredient by weight) was placed at each active burrow (loose dirt, fresh scats) in the experimental side of the colony. A placebo oat mixture identical to the above, but without DES, was administered to the control side. Because prairie dogs confine their activities to their coterie territory (Hoogland 1981), individuals of the same coterie probably ate only the oats in their particular territory.

The colony was treated twice during the first week of March, the period of peak breeding in 1981 and 1982. The placebo mixture was consumed more quickly than the DES mixture, suggesting that DES may impart an unattractive taste to the oats. However, all the bait was eaten within a week, possibly because little alternative foods was available during that time of year. Prairie dogs were the only animals observed feeding on the bait. 


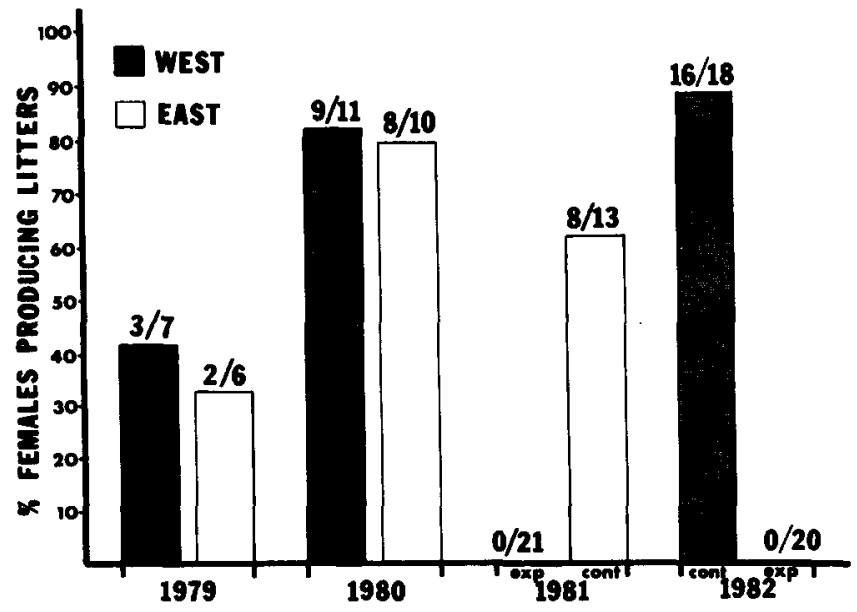

Fig. 2. Percentage of females producing litters for the 2 sides of the study colony during the 4-year study period. DES was administered during 1981 and 1982: experimental (exp) and control (cont) areas.

\section{Results and Discussion}

Reproduction was highly variable from one year to the next. For example, only 5 of the $13(38 \%)$ total females of the study colony produced litters in 1979 , but 17 of $21(81 \%)$ produced litters in 1980. However, productivity in these years was similar for the east and west sides of the colony ( $P=.54$, Fisher's Exact Test) (Fig. 2). In 1981,8 of $13(62 \%)$ females not treated with DES produced litters, whereas the treated females $(\mathrm{N}=21)$ were entirely unproductive. Pfeiffer (1972) attributed reproductive failure to embryo death and resorption. Results were similar in 1982 when DES treatment was reversed: the 20 treated females did not produce litters, whereas 16 of $18(89 \%)$ females treated with DES in 1981 brought up litters in 1982 (Fig. 1 and 2). For 1981 and 1982, reproduction was significantly less likely in the DES-treated sides of the colony $(P=.000$, Fisher's Exact Test). Of 7 females that produced litters in 1980, 6 $(86 \%)$ produced litters in 1982 , the year following their treatment with DES. Only 2 females that reproduced in 1979 were present on the west side in 1982; both produced litters.

Because the reproductive characteristics of yearlings can be different than those of adults, the number of yearling females in the population may affect the interpretation of results. The number of yearlings may affect the proportion of females producing litters. In both treatment years, there was a greater proportion of yearling females in the experimental group compared with the control group. Therefore, the control females may have been expected to reproduce more successfully than the experimental females. However, although King (1955) and Hoogland (1982) found that year-

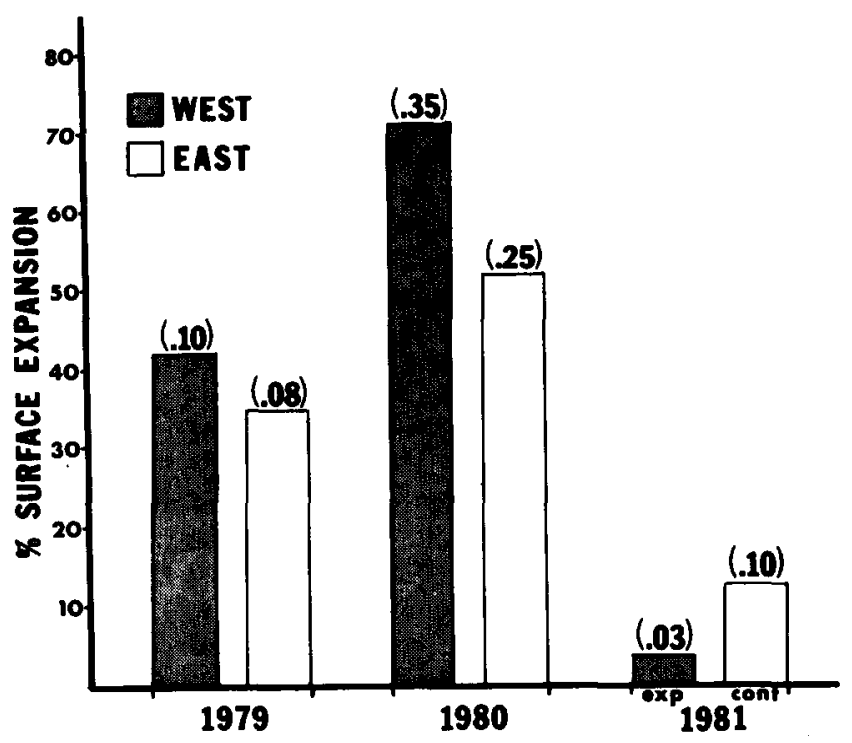

Fig. 3. Percentage surface expansion for the 2 sides of the study colony. Actual increases in surface area (ha) are indicated in parentheses.

lings do not usually breed, reproduction by yearlings was common in this particular colony (Garrett et al. 1982). Indeed, yearlings were more productive than adults of the control group in 1981 (Table 1). Koford (1958) suggested that food abundance was a more important factor in yearling reproduction than body weight or physiological ineptitude. Garrett et al. (1982) concluded that abundant food resulted in rapid development and high reproductive rates of prairie dogs at this colony.

The number of yearling-produced litters may also affect juvenile body weight. The juveniles produced by 16 adult females of the control group in 1982 weighed significantly less than those produced by 8 females of the control group in $1981(t=2.69, \mathrm{df}=95$, $P<.01$ ). Reduced juvenile weight in 1982 may have been a residual effect of the DES treatment to the females of the west side in 1981. However, mean weight of juveniles varied greatly between nontreatment years (Table 1). In addition, mean juvenile weight in litters produced by yearlings was significantly greater than adultproduced litters $(1980: t=56.68, \mathrm{df}=54, P<.001 ; 1981: t=3.23, d f=$ $28, P<.005)$. Because there were no yearling females present in the control group in 1982, mean juvenile weight was expected to be less compared with the control group in 1981 when yearlings were contributing heavier pups.

Litter size varied greatly between years and sides of the study colony, ranging from 2.8 on the east side in 1980 to 4.2 on the west (control) side in 1982 (Table 1). Because yearling litters tend to be

Table 1. Comparison of demographic properties between the two sides of the study colony. Numbers are mean \pm SD. Sample sizes are indicated by parentheses. (E) = Experimental Area $(C)=$ Control Area

\begin{tabular}{cccccc}
\hline \hline & & $\begin{array}{c}\text { \% Adult } \\
\text { reproduction }\end{array}$ & $\begin{array}{c}\text { \% Yearling } \\
\text { reproduction }\end{array}$ & $\begin{array}{c}\text { Juvenile } \\
\text { weight (g) }\end{array}$ \\
\hline size
\end{tabular}

\footnotetext{
* Exact ages of study animals were unknown during the first year of study.

* There were no yearlings in 1982 because no litters were produced on the west side in 1981.
} 
smaller than adult litters, the large litter sizes in 1982 probably were due to lack of yearlings rather than to latent effects of previous DES treatment. In addition, females of the control group in 1982 had not been physiologically stressed with reproduction the previous year and, therefore, were expected to produce larger litters.

King (1955) found no direct relationship between density and colony expansion, perhaps because of the complexity of factors involved. However, he suggested that population pressure may be important influence on expansion. Koford (1958) reported a direct correlation between the appearance of juveniles and the time of major expansion. Before juvenile emergence in 1981, animal density was similar on both sides of the colony. After emergence, density had increased significantly in the control area compared with the DES-treated area (Exp. $=39.7$ animals $/$ ha [before and after]; Cont. $=28.1$ [before], 66.4 [after]; $X^{2}=7.99, \mathrm{df}=1, P<.005$ ). Although colony expansion on the west side was greater than the east in 1979 and 1980, expansion of the west side (experimental) was $4 \mathrm{X}$ less than that of the east (control) following DES treatment in 1981 (Fig. 3). Note that colony expansion in 1979 and 1980 somewhat reflects the proportion of females producing litters (see Fig. 2). These data suggested that expansion is related to animal density, and that control of prairie dogs' reproduction can reduce colony expansion.

\section{Conclusions}

Treatment of prairie dogs during the breeding season with DES inhibited production, and lower animal density resulted in reduced colony expansion. There seemed to be no adverse effects of DES the year following treatment. In previously treated individuals, there was no effect on the proportion of females reproducing, size of litters, or weight of juveniles.

Perhaps effective prairie dog management should involve an integrated approach; that is, use of rodenticide for initial reduction and irregular DES treatments thereafter to maintain the population at desirable levels. However, if the use of rodenticide is impossible or objectionable (e.g., national parks, captive populations), population reduction could be achieved with annual treatments of DES alone. This study was conducted on a small scale and under rigorous control. Until the effectiveness and efficiency of using DES on larger areas is confirmed, practical application of this chemosterilant must remain tentative.

\section{Literature Cited}

Allen, S.H. 1982. Bait consumption and diethylstilbestrol influence on North Dakota red fox reproductive performance. Wildl. Soc. Bull. 10:370-374.

Balser, D.S. 1964a. Antifertility agents in vertebrate pest control. p. 133137. In: J.W. Koehler (ed.) Proc. Second Vertebr. Pest Control Conf., Univ. Calif., Davis.

Balser, D.S. 1964b. Management of predator populations with anti-fertility agents. J. Wildl. Manage. 28:352-358.

Bennett, H.W., E.J. Underwood, and F.L.Shier. 1946. A specific breeding problem of sheep on subterranean clover pastures in Western Australia. Aust. Vet. J. 22:2-12.

Bonham, C.D., and A. Lerwick. 1976. Vegetation changes induced by prairie dogs on shortgrass range. J. Range Manage. 29:221-225.

Brooks, J.E. 1973. A review of commensal rodents and their control. p. 405-453. In: Critical Reviews in Environmental Control. Vol. 3, No. 4. New York.

Davis, D.E. 1961. Principles for population control by gametocides. Trans. N. Amer. Wildl. Conf. 26:160-167.
Foreman, D.1962. The normal reproductive cycle of the female prairie dog and the effects of light. Anat. Rec. 142:391-405.

Garrett, M.G. 1982. Dispersal of black-tailed prairie dogs (Cynomys ludovicianus) in Wind Cave National Park, South Dakota. M.S. Thesis, lowa State Univ., Ames.

Garrett, M.G., J.L. Hoogland, and W.L. Franklin. 1982. Demographic differences between an old and a new colony of black-tailed prairie dogs (Cynomys ludovicianus). Amer. Midl. Natur. 108:51-59.

Hansen, R.M., and I.K. Gold. 1977. Blacktail prairie dogs, desert cottontails and cattle trophic relations on shortgrass range. J. Range Manage. 30:210-214.

Hoogland, J.L. 1977. The evolution of coloniality in white-tailed and black-tailed prairie dogs (Sciuridae: Cynomys leucurus and $C$. ludovicianus). Ph.D. Diss. Univ. Mich., Ann Arbor.

Hoogland, J.L. 1979. Aggression, ectoparasitism, and other possible costs of prairie dog (Sciuridae: Cynomys spp.) coloniality. Behaviour 69:1-35.

Hoogland, J.L. 1981. Nepotism and cooperative breeding in the blacktailed prairie dog (Sciuridae: Cynomys ludovicianus). p. 283-310. In: R.D. Alexander and D.W. Twinkle (eds.) Natural Selection and Social Behavior. Chiron Press, New York.

Hoogland, J.L. 1982. Prairie dogs avoid extreme inbreeding. Science 215:1639-1641.

Howard, W.E. 1967. Biological control of vertebrate pests. p. 137-157. In: M.W. Cummings (ed.) Proc. Third Vertebr. Pest Conf., Univ. Calif., Davis.

Howard, W.E., and R.E. Marsh. 1969. Mestranol as a reproductive inhibitor in rats and voles. J. Wildl. Manage. 33:403-408.

King, J.A. 1955. Social behavior, social organization, and population dynamics in a black-tailed prairie dog town in the Black Hills of South Dakota. Contrib. Lab. Vertebr. Biol. 67., Univ. Mich., Ann Arbor.

Klatt, L.E., and D. Hein. 1978. Vegetative differences among active and abandoned towns of black-tailed prairie dogs (Cynomys ludovicianus). J. Range Manage. 31:315-317.

Knipling, E.F, and J.J. McGuire. 1972. Potential role of sterilization for suppressing rat populations. USDA Tech. Bull. 1455.

Koford, C.B. 1958. Prairie dogs, whitefaces, and blue grama. Wildl. Monogr. 3:1-78.

Linhart, S.B., and R.K. Enders. 1964. Some effects of diethylstilbestrol on reproduction in captive red fox. J. Wildl. Manage. 28:358-363.

Marsh, R.E. 1973. Potential chemosterilants for controlling rats. Beih. ange. Zool. 3:191-198.

Marsh, R.E., and W.E. Howard. 1969. Evaluation of mestranol as a reproductive inhibitor of Norway rats in garbage dumps. J. Wildl. Manage. 33:133-138.

Marsh, R.E., and W.E. Howard. 1970. Chemosterilants as an approach to rodent control. p. 55-63. In: R.H. Dana (ed.) Proc. Fourth Vertebr. Pest Conf. Univ. Calif., Davis.

Marsh, R.E., and W.E. Howard. 1973. Prospects of chemosterilant and genetic control of rodents. Bull. WHO 48:309-316.

Marsh, R.E., and W.E. Howard. 1976. New perspectives in rodent and mammal control. p. 317-329. In: J.M. Sharpley and A.M. Kaplan (eds.) Proc. Third Int. Biodegradation Symp. Sci. Pub. Ltd., London.

Pfeiffer, D.G. 1972. Effects of diethylstilbestrol on reproduction in the black-tailed prairie dog. M.S. Thesis, South Dakota State Univ., Brookings.

Saunders, F.J. 1968. Effect of sex steroids and related compounds on the course of pregnancy. Physiol. Rev. 48:601-643.

Storm, G.L., and G.C. Sanderson. 1969. Results of a field test to control striped skunks with diethylstilbestrol. Trans. 111. State Acad. Sci. 62:193-197.

Tllestone, J.V., and R.K. Lechleitner. 1966. Some comparisons of the black-tailed and white-tailed prairie dogs in north-central Colorado. Amer. Midl. Natur. 75:292-316.

Truvis, H.G., and P.J. Schaible. 1962. Effect of diethylstilbestrol fed periodically during gestation of female mink upon reproduction and kit performance. Amer. J. Vet. Res. 23:359-361.

Trenkle, A., and W. Burroughs. 1978. Physiological effects of estrogens in animal feeds with emphasis on growth in ruminants. p. 577-611. In: J.N. Hathcock and J. Coon (eds.) Nutrition and Drug Interrelations. Academic Press, New. York. 